\title{
Publisher Correction: The supply chain of violence
}

Nathalie Butt $\mathbb{B}$, Frances Lambrick, Mary Menton and Anna Renwick

Correction to: Nature Sustainability https://doi.org/10.1038/s41893-019-0349-4, published online 5 August 2019.

In the version of this Article originally published, the colour shading of some of the countries in Fig. 2a was incorrect and should have been as shown below. This has now been corrected in the Article.
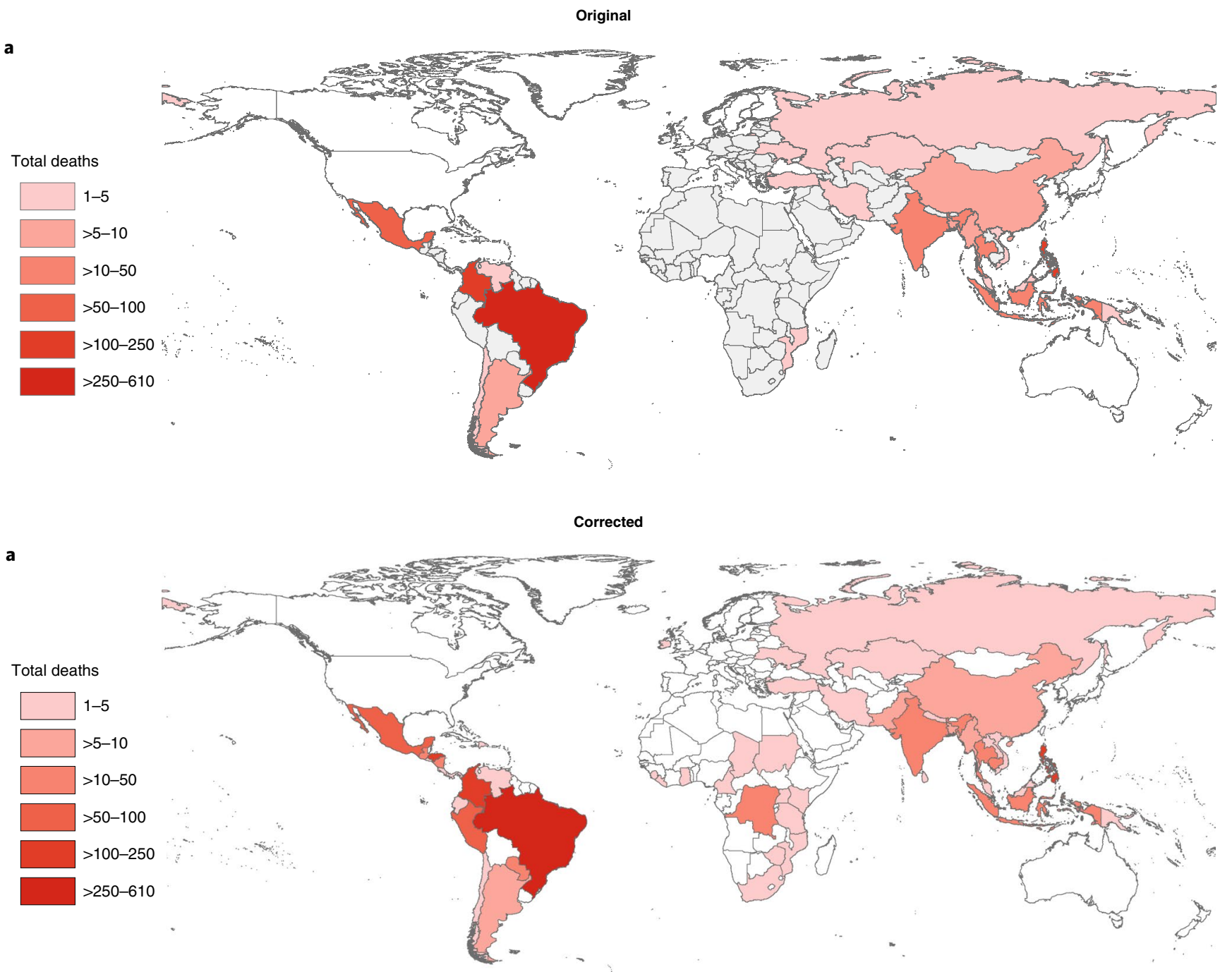

Fig. 2a | Original and corrected.

Published online: 21 August 2019

https://doi.org/10.1038/s41893-019-0379-y 